\title{
Knowledge of Medical Communication-Skills Among Pre-clinical Undergraduate Medical Students: a pre-test post-test experimental study.
}

Sameer Timilsina ( $\nabla$ sawmer@gmail.com )

Chitwan Medical College https://orcid.org/0000-0002-1563-9064

Sirisa MD Karki

Chitwan Medical College

Barun Shrestha

Chitwan Medical College

Gopendra Prasad Deo

Chitwan Medical College

Research article

Keywords: communication-skill, knowledge, medical, undergraduate

Posted Date: April 9th, 2020

DOI: https://doi.org/10.21203/rs.3.rs-20870/v1

License: (c) (i) This work is licensed under a Creative Commons Attribution 4.0 International License.

Read Full License 


\section{Abstract}

Background Effective physician-patient communication is integral to building confidence, improving compliance, satisfaction and avoiding mishaps and malpractice suits. Communication-skills (CS) training is an internationally accepted essential component of medical education. This study aims to assess the communication-skills knowledge of pre-clinical undergraduate medical students pre- and postCS course. We expect an improvement in CS knowledge post-intervention. Methods Between March and September 2019, 100 first year pre-clinical undergraduate medical students at Chitwan Medical College were enrolled in CS course. Attitude towards learning CS using communication skills attitude scale (CSAS) and assessment on knowledge of CS was conducted pre- and post-intervention. The intervention included 10 team-based learning (TBL) sessions on selective study areas based on Calgary-Cambridge model. Additionally, students' demographic profile was collected at the start of the intervention. Results Among 100 students, $70 \%$ were males and 30\% females. Positive attitude towards learning CS improved by $5 \%$. Statistically significant progress was noted in post-intervention mean scores implying CS to be teachable and learnable. (Wilcoxon Signed ranks test $z=-6.178 p<0.001$ ). Knowledge on medical CS improved in the study participants irrespective of sex, entry-type, past-educational institute or attitude. Students with pre-intervention negative attitude showed marked improvement in post-intervention knowledge score $(z=-5.674 p<0.001)$. Conclusion The intervention was effective in increasing students' knowledge of medical CS, but we did not assess the skills of the students. Continuation of this study is recommended to explore whether CS training could actually improve soft skills of medical students in our part of the world.

\section{Background}

The rising public expectation about their rights in the healthcare system has forced medical institutions across the world reform their medical curriculum. CS curriculum has now been incorporated into both the undergraduate and postgraduate syllabuses. CS during consultations are pivotal to patient-centred communication allowing the attending physician understand patient's perspective of illness and express empathy. In the past, undergraduate medical students in Nepal, acquired their CS knowledge entirely through observation of consultations by their supervisors. The introduction of CS curriculum into the undergraduate medical syllabus of Tribhuvan University (TU) in 2008 has highlighted the importance of effective doctor patient communication in Nepalese context. This is based on the evidence that effective doctor-patient communication is central to better patient outcomes, compliance, improving both doctor and patient satisfaction and avoiding legal issues.[1]

In the developed countries, medical educators have built a consensus regarding essential elements of CS applicable during medical consultations and appreciated the need to teach those skills to medical students early on. [2] Assessment of CS has been a part of licensing examinations further highlighting the value of this skill. It is important to note that the third world countries have only recently realized its importance. Also, a large number of medical students willing to pursue their medical career in developed countries have influenced the curriculum designers amend the curriculum. No formal CS teaching has 
begun in Nepal for undergraduate students and a few studies conducted report good attitude of students towards learning the same. Many medical students in Nepal aspire working in developed countries upon completion of their studies. To address this, we planned to teach CS to undergraduate medical students in early pre-clinical years. In the present study we aim to assess medical CS knowledge among undergraduate medical students pre- and post- CS course. We expect the student's knowledge to improve post-intervention.

\section{Methods}

A 3-day medical CS training conducted among fresh Year III medical students provided substantial evidence to conduct a year-long integrated knowledge-based CS course among preclinical undergraduate medical students. The course dictated by TU curriculum emphasized patient-centered communication. Ethical approval for the study was obtained from Institutional Review Committee- Chitwan Medical College (Ref: CMC-IRC/075/076-123). All 100 Year I students were invited to participate in the study on March 2019. A written consent obtained from the participants informed them of their rights to not participate in the study, and non-participation would not bear internal academic consequence. We instructed the students to complete a self-administered survey which included questions of sociodemographics (age, sex, entry-type and past educational institute). We divided the students into 10 groups of 10 students each and conducted 10 sessions on theoretical aspects of medical CS employing Team-Based Learning as teaching-learning method. Several didactic methods were used including lectures, PowerPoint presentation, e-books, video-tape, role-playing and small-group discussion. Selective study areas included building relationship, problem clarification integrated with specific history, obtaining consent, advising discharged patients for common conditions and arranging follow ups based on Calgary-Cambridge model.[3, 4] Both formative and summative assessments were used as assessment tools. Participants improvement in medical CS knowledge was assessed using pre- and post-intervention Single and Multiple-Choice questions, True-False statements constructed by a panel of experts. Attitude towards learning CS was assessed using CSAS. [5] Data were analyzed using SPSS version 21. Chisquared test was done to find the association between different demographic variables and attitude with knowledge scores. Wilcoxon Signed ranks test was done to assess the effectiveness of the intervention. The numerical values were expressed as mean \pm SD and categorical variables as percentage. Statistical significance was considered at $p<0.05$.

\section{Results}

The sample consisted of 100 premedical undergraduate students: 70 (70\%) males and $30(30 \%)$ females with age ranging between $17-21$ years (mean: $18.99 \pm 0.95$ years). Over $50 \%$ of the students had positive attitude towards learning CS. (Table 1 )

Table 1. Characteristics of Study Participants 


\begin{tabular}{|l|l|}
\hline Variable & Frequency (\%) \\
\hline Sex & $70(70 \%)$ \\
\hline Male & $30(30 \%)$ \\
\hline Female & $67(67 \%)$ \\
\hline Entry Type & $33(33 \%)$ \\
\hline Fresher & $15(15 \%)$ \\
\hline Old Batch & $85(85 \%)$ \\
\hline Past Educational Institute & Government Institute \\
\hline Private Institute & $52(52 \%)$ \\
\hline Communication Skills Attitude Scale (Pre-intervention) \\
\hline Positive Attitude & $48(48 \%)$ \\
\hline Negative Attitude
\end{tabular}

Knowledge on medical CS knowledge improved in the study participants irrespective of sex, entry-type, past-educational institute or attitude. (Table 2)

Table 2. Association between knowledge score and participant characteristics

\begin{tabular}{|c|c|c|c|c|c|}
\hline \multirow[t]{2}{*}{ Variable } & \multicolumn{3}{|c|}{ Knowledge Score } & \multirow[t]{2}{*}{$x^{2}$} & \multirow[t]{2}{*}{ p-value } \\
\hline & Positive $\mathrm{n}(\%)$ & Negative $\mathrm{n}(\%)$ & Tie n(\%) & & \\
\hline \multicolumn{6}{|l|}{ Sex } \\
\hline Male & $49(70)$ & $16(22.8)$ & $5(7.2)$ & -5.207 & 0.000 \\
\hline Female & $22(73.3)$ & $6(20)$ & $2(6.7)$ & -3.360 & 0.001 \\
\hline \multicolumn{6}{|l|}{ Entry-type } \\
\hline Fresher & $45(67.1)$ & $18(26.8)$ & $4(6.1)$ & -4.508 & 0.000 \\
\hline Old-batch & $26(78.7)$ & $4(12.1)$ & $3(9.2)$ & -4.217 & 0.000 \\
\hline \multicolumn{6}{|c|}{ Past Educational Institute } \\
\hline Private Institute & $66(77.6)$ & $16(18.8)$ & $3(3.6)$ & -6.352 & 0.001 \\
\hline Government Institute & $12(80)$ & $1(6.6)$ & $2(13.4)$ & -5.264 & 0.000 \\
\hline \multicolumn{6}{|c|}{ Communication Skills Attitude Scale } \\
\hline Positive & $28(53.8)$ & $18(34.6)$ & $6(11.6)$ & -2.295 & 0.022 \\
\hline Negative & $43(89.5)$ & $4(8.3)$ & $1(2.2)$ & -5.674 & 0.000 \\
\hline
\end{tabular}

Knowledge scored improved in both sets of students with either positive or negative attitude toward learning CS pre-intervention, however, students with pre-intervention negative attitude showed marked improvement in post-intervention knowledge score $(z=-5.674 p<0.001)$. There was a statistically significant improvement in post-intervention knowledge scores $(p<0.05)$. (Table 3$)$

Table 3. Effectiveness of intervention on communication skills learning attitude and knowledge

\begin{tabular}{|l|l|l|l|l|}
\hline Variable & \multicolumn{1}{|l|}{ Pre-intervention n (\%) } & Post-intervention n (\%) & $\chi^{2}$ & p-value \\
\hline Communication Skills Learning Attitude & $57(57)$ & 8.859 & 0.012 \\
\hline Positive Attitude & $52(52)$ & $43(43)$ & & \\
\hline Negative attitude & $48(48)$ & $27.93 \pm 5.58$ & & \\
\hline Knowledge Scores & $23.16 \pm 4.95$ & -6.178 & 0.000 \\
\hline
\end{tabular}




\section{Discussion}

Transition from "physician-centred" to "patient-centred" approach of treatment in our context of "see-doteach" themed medical school is challenging. The challenge of teaching CS is daunting as this soft skill is thought unteachable, unlearnable and that skills acquired during the training period tends to decline over time[6]. The high level of student participation during the initial stages of the intervention was unexpected but encouraging. Our students were not exposed to any form of such formal training so they valued this unique opportunity indicating early sensitivity towards this crucial trait. The never-ending litigations against doctors with poor CS could be another factor driving students to enrol in the intervention. Also, newly admitted medical students could have unrealistic and high notions regarding importance of CS. It suggested early need of intervention among medical students.[1, 7]

Lectures, PowerPoint presentations, e-books, video-tape, role-playing and small-group discussions were used as teaching learning methods in our intervention. Various strategies have been used worldwide in teaching medical CS with one superior to the other.[8,9] We opted inexpensive methods over CS labs and simulated patients (SP) due to financial constraints. All the study materials were in accordance with the TU curriculum, Calgary-Cambridge model and Kalamazoo Essential Elements Communication Checklists. $[3,4]$

There are conflicting reports on change in attitude of medical students post-CS course.[10] Our study reported improvement in learning attitude post-intervention[11] as evidenced by CSAS score indicating attitude to be a learned response amenable to change. Dissimilar reports could have been because of different context and intervention methods.

In the present study, we employed TBL and small group teaching as teaching-learning method. Though small group teaching puts huge work burden on the trainer, only one trainer was utilized to minimize trainer discrepancies between groups.[1] Also, evaluation was conducted by other investigators to avoid biasness. Most medical schools in our part of the world use English as primary instructional method. The patients, however, use native language for communication during medical consultation. We employed Nepali language as both instructional and assessment method. The impact of using native language as instructional method has not been studies. On one hand it could be fruitful for future doctors wanting to work in Nepal but, on the other hand could not be as productive to foreign aspirants.

Defying CS learning as unteachable and unlearnable myth, students' performance improved significantly in post-interventional summative assessment scores, highlighting the effectiveness of early intervention. There was statistically significant improvement in knowledge scores in either sex, entry-type or past educational institute. This suggests every type of medical students could learn CS. Studies have shown a decline in CS of medical students with passing years. The present study needs to be more comprehensive to extract such a conclusion. Improvement in knowledge has been assessed using various strategies like OSCE (Objective Structured Clinical Examination),[12, 13] SP[13], True False Statements, Multiple and Single Choice Questions. No goal standard assessment model has been suggested as different assessment methods have different values. $[8,9,14]$ Use of SP's and CS-lab has been widely reported in 
literature to evaluate CS of the students. The lack of funds hindered both our intervention and evaluation plan with SP's using CS-lab.

The early enthusiasm with encouraging participation was short-lived. During subsequent formative assessments, the progress and assessment scores were not promising. High-stake knowledge-based exams in our part of world could avert medical students towards learning CS. Also, TU provision of Not Fit for Technical education (NFTE) after 5 unsuccessful passing attempts in other basic science subjects could help lack motivation to studying CS.

\section{Conclusion}

Effective doctor-patient communication is a core physician competency fundamental to establishing relationship, successful diagnosis and treatment, and both doctor-patient satisfaction. Since CS can be learned and mastered by either gender, freshmen or old batch irrespective of past educational institute, it is worthwhile imparting the knowledge since early undergraduate years. CS training with visits to health centres and early patient exposure may benefit better students learning. This study can be replicated in other medical institutes to confirm the findings.

\section{Abbreviations}

CSAS

Communication Skills Attitude Scale

CS

Communication Skills

\section{Declarations}

\section{-Ethics approval and consent to participate}

Ethical approval was obtained from Institutional Review Committee- Chitwan Medical College (Ref: CMCIRC/075/076-123). Written consent was obtained from all the palliative patients for participation in the study. The consent also informed the participants that the data obtained could be used and made public under anonymity. All procedures were in accordance with the Helsinki declaration and its later amendments.

\section{-Consent for publication}

Not Applicable

\section{-Availability of data and material}

The datasets obtained and/or analyzed during the current study are not publicly available due to confidentiality consent of the study but can be obtained from the corresponding author on reasonable 
request.

\section{-Competing interests}

The authors declare that they have no competing interests.

\section{-Funding}

No funding of any sort was received for the study. The investigators shared the cost of the project.

\section{-Authors' contribution}

ST conceptualized the study, obtained ethical approval, conducted the whole project and prepared the original draft of the study. SK participated in data collection, data analysis and revising the draft. BS contributed in data analysis, methodology, assessment of the participants and reviewing and editing the manuscript. GPD prepared the methodology, conducted and evaluated assessments and administered the project. All authors read and approved the final manuscript.

\section{-Acknowledgements}

We would like to thank Chairman and Managing Director of Chitwan Medical College and CMC-IRC for having allowed us to conduct the study at this institution. We would also like to thank our fellow colleagues at School of Medicine, CMC for all the help and support. Nonetheless, our sincere gratitude to all the participants in the study without whom it would have been impossible to conduct the study.

\section{References}

1. Deveugele M, Derese A, De Maesschalck S, Willems S, Van Driel M, De Maeseneer J. Teaching communication skills to medical students, a challenge in the curriculum? Patient Educ Couns. 2005;58(3):265-70.

2. King A, Hoppe RB. "Best practice" for patient-centered communication: a narrative review. J Grad Med Educ. 2013;5(3):385-93.

3. Kurtz SM, Silverman JD, Draper J. Teaching and Learning Communication Skills in Medicine. In. Oxford: Radcliffe Medical Press; 1998.

4. Silverman JD, Kurtz SM, Draper J: Skills for Communicating with Patients. In.: Radcliffe Medical Press (Oxford); 1998.

5. Rees C, Sheard C, Davies S. The development of a scale to measure medical students' attitudes towards communication skills learning: the Communication Skills Attitude Scale (CSAS). Medical education. 2002;36(2):141-7.

6. Joekes K, Noble LM, Kubacki AM, Potts HWW, Lloyd M. Does the inclusion of 'professional development' teaching improve medical students' communication skills? BMC medical education. $2011 ; 11: 41-1$. 
7. Baerheim A, Hjortdahl P, Holen A, Anvik T, Fasmer OB, Grimstad H, Gude T, Risberg T, Vaglum P. Curriculum factors influencing knowledge of communication skills among medical students. BMC Med Educ. 2007;7:35.

8. Rees C, Sheard C, McPherson A: Communication skills assessment: the perceptions of medical students at the University of Nottingham. Medical education 2002, 36(9):868-878.

9. Liew SC, Dutta S, Sidhu JK, De-Alwis R, Chen N, Sow CF, Barua A. Assessors for communication skills: SPs or healthcare professionals? Med Teach. 2014;36(7):626-31.

10. Moral RR, García de Leonardo C, Caballero Martínez F, Monge Martín D. Medical students' attitudes toward communication skills learning: comparison between two groups with and without training. Adv Med Educ Pract. 2019;10:55-61.

11. Jin HK, Park SH, Kang JE, Choi KS, Kim HA, Jeon MS, Rhie SJ. The influence of a patient counseling training session on pharmacy students' self-perceived communication skills, confidence levels, and attitudes about communication skills training. BMC Med Educ. 2019;19(1):172.

12. Cave J, Washer P, Sampson P, Griffin M, Noble L. Explicitly linking teaching and assessment of communication skills. Med Teach. 2007;29(4):317-22.

13. Choudhary A, Gupta V. Teaching communications skills to medical students: Introducing the fine art of medical practice. Int J Appl Basic Med Res. 2015;5(Suppl 1):41-4.

14. Rider EA, Hinrichs MM, Lown BA. A model for communication skills assessment across the undergraduate curriculum. Med Teach. 2006;28(5):e127-34. 